\title{
ANALISIS PENGARUH KUALITAS PRODUK DAN KUALITAS PELAYANAN TERHADAP KEPUTUSAN PEMBELIAN PRODUK TANGKI PENGUIN DI JAKARTA
}

\author{
Imron Imron \\ Fakultas Teknik dan Informatika, Program Studi Sistem Informasi \\ Universitas Bina Sarana Informatika \\ Email: imron.imr@bsi.ac.id
}

\begin{abstract}
ABSTRAK
Penelitian ini dimaksudkan untuk mengetahui pengaruh baik secara simultan dan parsial, sejauh mana keputusan pembelian mempunyai pengaruh terhadap kualitas produk dan kualitas pelayanan pada PT. Penguin Indonesia. Dan variabel mana yang memberi kontribusi terbesar terhadap keputusan pembelian. Kualitas Produk adalah totalitas fitur dan karakteristik produk atau jasa yang bergantung pada kemampuannya untuk memuaskan kebutuhan yang dinyatakan atau tersirat. Kualitas Pelayanan keunggulan layanan dapat dibentuk melalui pengintegrasian empat pillar service excellence yang saling berkaitan erat, yaitu: kecepatan, ketepatan, keramahan, dan kenyamanan pelayanan. Keputusan Pembelian adalah proses pengintegrasian yang dikombinasikan dua atau lebih prilaku alternatif dan memilih salah satu diantaranya.
\end{abstract}

Kata kunci: kualitas produk, kualitas pelayanan, keputusan pembelian, penelitian ilmiah, SPSS, tangki penguin

\begin{abstract}
This study aimed to determine the effect both simultaneously and partially, the extent to which the purchase decision has an effect on product quality and service quality at PT. Penguin Indonesia. And which variables are the largest contributors to the purchasing decision. Product Quality is the totality of features and characteristics of the products or services that depend on its ability to satisfy stated or implied needs. Service Quality of service excellence can be formed through the integration of the four pillars of service excellence closely interrelated, namely: speed, accuracy, friendliness, and comfort care. Purchasing decisions are combined process of integrating two or more alternative behaviors and choosing one of them. This study used a survey design and research methods associative.
\end{abstract}

Keywords: quality products, quality wervice, purchase decision, scientific research, SPSS, penguin tank

\section{PENDAHULUAN}

Perkembangan dunia bisnis yang semakin ketat menuntut perusahaan harus mampu bergerak cepat dan tepat agar mampu menghadapi persaingan. Syarat yang harus dipenuhi oleh suatu perusahaan agar dapat sukses dalam persaingan adalah berusaha mencapai tujuan untuk menciptakan dan mempertahankan pelanggan. Persaingan bisnis saat ini dapat dibuktikan dengan semakin banyaknya perusahaan-perusahaan sejenis yang menawarkan produk yang sama. Sehingga hal ini membuat perusahaan yang lain akan memacu persaingan yang semakin ketat, karena perusahaan sejenis akan berlomba-lomba untuk lebih kreatif dan inovatif dalam menjual produknya, dalam hal ini adalah Produk Tangki Penguin. Perbaikan kualitas produk akan mengurangi biaya dan meningkatkan keunggulan bersaing yang bertahan lama. Oleh karena itu kualitas produk dan 
kualitas pelayanan merupakan faktor penting yang mendorong pertumbuhan ekonomis perusahaanperusahaan dimanapun dalam konteks pasar global.

Segala sesuatu yang berhubungan dengan manusia setiap kali akan mengalami perubahan, baik dalam bidang politik, ekonomi, sosial, budaya dan juga pengaruh pada pola prilaku pesaing didalam menjalankan bisnisnya. Hal ini mengakibatkan pesaingan semakin ketat dalam dunia bisnis, setiap perusahaan pada umumnya ingin berhasil dalam menjalankan usahanya. [2]

Berdasarkan latar belakang masalah yang telah dikemukakan, maka masalah yang dapat menyebabkan keputusan pembelian adalah terdapat indikasi, bagaimana perusahaan tetap menghasilkan produk yang berkualitas dan kualitas pelayanan baik dengan persaingan bisnis yang begitu ketat tanpa mengurangi kualitas produk yang dihasilkan. Terdapat indikasi belum adanya peneliti yang menganalisis keputusan pembelian produk tangki air dan variabel manakah diantara kualitas produk dan kualitas pelayanan yang mempunyai pengaruh paling dominan terhadap keputusan pembelian produk tangki Penguin.

Didalam penelitian analisis pengaruh kualitas produk dan kualitas pelayanan, fokus penelitian ini lebih pada perilaku konsumen sebelum memutuskan membeli suatu produk dalam hal ini produk tangki Penguin, dan faktor apa saja yang dominan mempengaruhi konsumen dalam mengambil keputusan pembelian.

Hipotesa dalam penelitian ini adalah sebagai berikut:

$\mathrm{H}_{0}$ : Terdapat pengaruh positif antara kualitas produk terhadap keputusan pembelian.

$\mathrm{H}_{1}$ : Tidak terdapat pengaruh positif antara kualitas produk terhadap keputusan pembelian.

$\mathrm{H}_{2}$ : Terdapat pengaruh positif antara kualitas pelayanan terhadap keputusan pembelian.

$\mathrm{H}_{3}$ : Tidak Terdapat pengaruh positif antara kualitas pelayanan terhadap keputusan pembelian.

$\mathrm{H}_{4}$ : Terdapat pengaruh positif antara kualitas produk dan kualitas pelayanan terhadap keputusan pembelian.

$\mathrm{H}_{5}$ : Tidak terdapat pengaruh positif antara kualitas produk dan kualitas pelayanan terhadap keputusan pembelian.

\section{METODOLOGI PENELITIAN}

\section{a. Observasi}

Metode penelitian lapangan dimana penelitian didasarkan pada pengumpulan data dari lapangan dari lapangan yang menjadi objek penelitian dalam hal ini PT. Penguin Indonesia.

\section{b. Wawancara (Interview)}

Dalam pengumpulan data ini, penulis melakukan wawancara dengan Pimpinan PT. Penguin Indonesia yang dalam hal ini diwakilli oleh Wakil Quality Management Representative, yang memiliki fungsi jabatan, mewakili manajemen perusahaan dalam pengembangan, penerapan dan pemeliharaan sistem manajemen mutu perusahaan termasuk penyelesaian masalah yang berhubungan dengan mutu, bertanggung jawab atas penerapan dan pemeliharaan sistem manajemen mutu perusahaan yang ditetapkan secara menyeluruh.

\section{c. Data Kuesioner}

Pengumpulan data dengan cara menyebarkan daftar pertanyaan yang berhubungan dengan penelitian kepada responden yang ada. Hal ini yang dimaksudkan agar penulis mendapatkan umpan balik dari konsumen untuk kepentingan penelitian ini. Populasi yang digunakan dalam penelitian ini adalah para konsumen produk Penguin terdiri dari konsumen langsung. Jumlah responden yang diambil sebanyak 33 responden.

\subsection{Landasan Teori}




\section{a. Uji Validitas}

Uji signifikasi dilakukan dengan membandingkan nilai $\mathrm{r}$ hitung (nilai Corrected Item - Total Correlation pada output Cronbach Alpha) dengan nilai $\mathrm{r}$ tabel degree of freedom $(\mathrm{df})=\mathrm{n}-\mathrm{k}$, dalam hal ini merupakan jumlah sampel dan k merupakan jumlah variabel independent. [2]

\section{b. Uji Reabilitas}

Untuk mengukur konsistensi konstruk atau indikator (variabel) penelitian. Suatu kuesioner dikatakan reliabel atau handal jika jawaban seseorang terhadap peryataan adalah konsisten atau stabil dari waktu ke waktu. [2]

\subsubsection{Pengujian Asumsi Klasik}

\section{a. Multikolinieritas}

Multikolineritas dapat dideteksi dengan menghitung koefisensi korelasi ganda dan membandingkannya dengan koefisiensi antar variabel bebas. Mengungkapkan sesuatu yang akan diukur oleh kuesioner tersebut. [8]

\section{b. Autokorelasi}

Autokorelasi adalah korelasi diantara anggota seri dari observasi-obeservasi yang diurutkan berdasarkan waktu. Dalam kaitannya dengan asumsi OLS, autokorelasi merupakan korelasi antara satu variabel gangguan dengan variabel gangguan lain. [1]

\section{c. Regresi Linier Berganda}

Analisis regresi berganda dipakai untuk untuk mengetahui besarnya pengaruh variabel bebas terhadap variabel [9]. Uji koefisiensi determinasi (R2) digunakan untuk mengukur seberapa jauh kemampuan model dalam menerangkan keputusan pembelian. Uji F, Digunakan untuk mengetahui apakah variabel-variabel independen secara simultan berpengaruh signifikasi terhadap variabel dependent. Uji T, Digunakan untuk mengetahui apakah variabel-variabel independen secara parsial berpengaruh nyata atau tidak terhadap variabel dependent.

\subsubsection{Tinjauan Organisasi/Objek Penelitian}

Penelitian ini merupakan penelitian asosiatif dan eksplansi, yaitu penelitian dengan penjelasan pengaruh, metode penelitian adalah analisis deskriptif, dimana data dikumpulkan, disusun, diintrepertasikan, dan dianalisis sehingga memberikan keterangan yang lengkap bagi masalah yang dihadapi. Penelitian ini dilakukan pada PT. Penguin Indonesia yang beralamat di Jln. Kapuk Kamal Muara IX No. 28A.

\subsection{Tahapan Penelitian Penelitian}




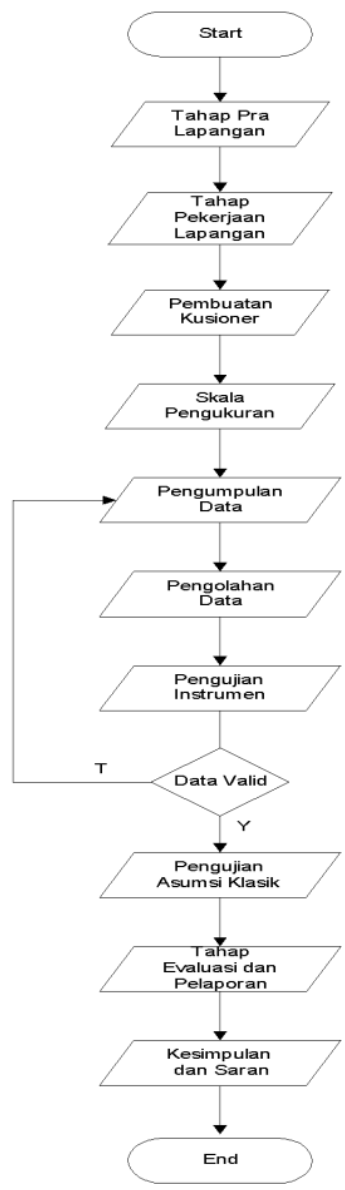

\section{Gambar 1. Flowchart Tahapan Penelitian}

Penelitian ini meneliti dua variabel independen yaitu kualitas produk (sebagai variabel $\mathrm{X}_{1}$ ), kualitas pelayanan (sebagai variabel $\mathrm{X}_{2}$ ) dan satu variabel dependency yaitu keputusan pembelian (sebagai variabel Y) akan dijelaskan sebagai berikut:

\subsubsection{Variabel Kualitas $\left(X_{1}\right)$}

\subsubsection{Definisi Konseptual Variabel Kualitas Produk}

Kualitas produk adalah totalitas fitur dan karakteristik produk atau jasa yang bergantung pada kemampuannya untuk memuaskan kebutuhan yang dinyatakan atau tersirat. Ada delapan dimensi dari kualitas produk yaitu: (1) kinerja (performance), (2) bagian-bagian tambahan dari produk (feature), (3) kehandalan (reability), (4) kesesuaian karakteristik operasi produk-produk dengan spesifikasi tertentu atau tidak ada cacat produk (conformance), (5) ketahanan (durability), (6) pelayanan (service ability), (7) estetika (aesthetic) dan (8) kesan kualitas (perceived quality). 


\subsubsection{Definisi Operasional Variabel Kualitas Produk}

Kualitas produk diukur dengan menggunakan indikator (1) kinerja (performance), (2) bagianbagian tambahan dari produk (feature), (3) kehandalan (reability), (4) kesesuaian karakteristik operasi produk-produk dengan spesifikasi tertentu atau tidak ada cacat produk (conformance), (5) ketahanan (durability), (6) pelayanan (service ability), (7) estetika (aesthetic) dan (8) kesan kualitas (perceived quality).

\subsubsection{Kisi-Kisi Instrument Kualitas Produk}

\begin{tabular}{|c|c|c|}
\hline Dimensi & Indikator & $\begin{array}{c}\text { Butir Soal } \\
\text { Angket }\end{array}$ \\
\hline performance & $\begin{array}{l}\text { Manfaat utama } \\
\text { produk yang } \\
\text { dibeli. }\end{array}$ & 1,2 \\
\hline feature & $\begin{array}{c}\text { Penampilan } \\
\text { produk yang } \\
\text { menarik. }\end{array}$ & 3,4 \\
\hline reability & $\begin{array}{l}\text { Ketepatan } \\
\text { produk yang } \\
\text { dibeli. }\end{array}$ & 5,6 \\
\hline conformance & $\begin{array}{l}\text { Daya tahan } \\
\text { produk yang } \\
\text { dibeli memiliki } \\
\text { standar kualitas } \\
\text { yang tinggi. }\end{array}$ & 7 \\
\hline durability & $\begin{array}{c}\text { Keawetan } \\
\text { produk yang } \\
\text { dibeli, memiliki } \\
\text { umur ekonomis } \\
\text { yang lama. }\end{array}$ & 9,10 \\
\hline Service ability & $\begin{array}{c}\text { Produk yang } \\
\text { dibeli bisa } \\
\text { diperbaiki. }\end{array}$ & 11 \\
\hline aesthetic & $\begin{array}{c}\text { Keanekaragama } \\
\mathrm{n} \text { bentuk dan } \\
\text { design. }\end{array}$ & 12,13 \\
\hline perceived quality & $\begin{array}{l}\text { Kesesuaian } \\
\text { persepsi kualitas } \\
\text { produk, merk, } \\
\text { dan daya tahan } \\
\text { produk }\end{array}$ & $8,14,15$ \\
\hline
\end{tabular}

\subsubsection{Uji Coba Instrument Kualitas Produk}

Pengujian instrument kualitas produk untuk memilih untuk memilih butir-butir instrument yang valid dan reliable.

\section{a. Pengujian Validitas}


Validitas yang diukur adalah validitas internal consistency dengan menggunakan rumus korelasi product moment. Antara skor butir soal dengan skor total.

$$
r b=\frac{n \sum X Y-\left(\sum X\right)\left(\sum Y\right)}{\sqrt{\left[n \sum X^{2}-\left(\sum X\right)^{2}\right]\left[n \sum Y^{2}-\left(\sum Y\right)^{2}\right]}}
$$

Keterangan:

rb : Koefisien Korelasi Pearson Product Moment

$\mathrm{X} \quad$ : Skor item instrument yang akan digunakan

$\mathrm{Y} \quad$ : Skor semua item instrument dalam variabel tersebut

$\mathrm{n} \quad$ : Jumlah responden dalam uji coba instrument

Kriteria pengujian ditetapkan dengan cara membandingkan $r_{\text {hitung }}$ lebih besar dari $r_{\text {tabel }}$ maka butir instrument dikatakan valid, begitu sebaliknya $r_{\text {hitung }}$ lebih kecil atau sama dengan $r_{\text {tabel }}$ maka butir dinyatakan tidak valid (drop) sehingga tidak dapat digunakan untuk penelitian.

\section{b. Pengujian Reliabilitas}

Butir instrument yang telah dinyatakan valid tersebut kemudian dihitung reliabilitasnya, dengan menggunakan koefisien alpha cronbach, koefisien reabilitasnya instrumentt yang dihasilkan apakah cukup atau tidak yang berarti instrument kualitas produk tersebut sudah dapat digunakan untuk pengambilan data penelitian.

$$
\boldsymbol{\alpha}=\frac{k}{k-1}\left(1-\frac{\sum S^{2} t}{S^{2} t}\right)
$$

Keterangan

a : Reabilitas Alpha Cronbach

$\mathrm{k} \quad$ : Jumlah butir instrument

$\sum S^{2} t$ : Jumlah varian butir

$S^{2} t \quad$ : Varian total

Varian butir ditentukan dengan rumus

$$
\sigma=\frac{\sum X^{2} \frac{\left(\sum X\right)^{2}}{n}}{n}
$$

Analisis dilakukan dari seluruh instrument. Kriteria pengujiannya adalah apabila nilai $\mathbf{r}_{\text {hitung }}>$ $\mathrm{r}_{\text {tabel }}$ maka intrument dinyatakan reliabel dan sebaliknya apabila nilai $\mathrm{r}_{\text {hitung }}<\mathrm{r}_{\text {tabel }}$ maka instrument dinyatakan tidak reliabel.

\subsubsection{Variabel Kualitas Pelayanan $\left(X_{2}\right)$}

\subsubsection{Definisi Konseptual Variabel Kualitas Pelayanan}

Keunggulan pelayanan dapat dibentuk melalui pengintegrasian empat pilar service excellence yang saling berkaitan erat yaitu kecepatan, ketepatan, keramahan, dan kenyamanan pelayanan.

\subsubsection{Definisi Operasional Variabel Kualitas Pelayanan}


Kualitas pelayanan diukur dengan menggunakan indikator (1) kecepatan, (2) ketepatan, (3) keramahan, dan (4) kenyamanan pelayanan.

\subsubsection{Kisi-Kisi Instrument Kualitas Pelayanan}

Tabel 2. Kisi-Kisi Variabel Kualitas Pelayanan

\begin{tabular}{|c|c|c|}
\hline Dimensi & Indikator & $\begin{array}{c}\text { Butir Soal } \\
\text { Angket }\end{array}$ \\
\hline Kecepatan & $\begin{array}{l}\text { Kecepatan } \\
\text { layanan. }\end{array}$ & $1,2,3$ \\
\hline Ketepatan & $\begin{array}{c}\text { Keakuratan } \\
\text { administrasi. }\end{array}$ & 5,6 \\
\hline Keramahan & $\begin{array}{c}\text { Keramahan } \\
\text { Pegawai \& } \\
\text { kompetensi } \\
\text { karyawan } \\
\text { menjelaskan } \\
\text { produk. }\end{array}$ & 7,8 \\
\hline $\begin{array}{l}\text { Kenyamana } \\
\mathrm{n} \\
\text { Pelanyanan }\end{array}$ & $\begin{array}{c}\text { Kemudahan } \\
\text { dalam } \\
\text { menghubungi dan } \\
\text { memahami } \\
\text { kebutuhan } \\
\text { pelanggan. }\end{array}$ & $4,9,10$ \\
\hline
\end{tabular}

\subsubsection{Uji Coba Instrument Kualitas Pelayanan}

Pengujian instrument kualitas pelayanan untuk memilih untuk memilih butir-butir instrument yang valid dan reliable.

\section{a. Pengujian Validitas}

Validitas yang diukur adalah validitas internal consistency dengan menggunakan rumus korelasi product moment. Antara skor butir soal dengan skor total.

$$
r b=\frac{n \sum X Y-\left(\sum X\right)\left(\sum Y\right)}{\sqrt{\left[n \sum X^{2}-\left(\sum X\right)^{2}\right]\left[n \sum Y^{2}-\left(\sum Y\right)^{2}\right]}}
$$

rb : Koefisien Korelasi Pearson Product Moment

$\mathrm{X} \quad$ : Skor item instrument yang akan digunakan

Y : Skor semua item instrument dalam variabel tersebut

$\mathrm{n} \quad$ : Jumlah responden dalam uji coba instrument

Kriteria pengujian ditetapkan dengan cara membandingkan $r_{\text {hitung }}$ lebih besar dari $r_{\text {tabel }}$ maka butir instrument dikatakan valid, begitu sebaliknya $r_{\text {hitung }}$ lebih kecil atau sama dengan $r_{\text {tabel }}$ maka butir dinyatakan tidak valid (drop) sehingga tidak dapat digunakan untuk penelitian.

\section{b. Pengujian Reliabilitas}

Butir instrument yang telah dinyatakan valid tersebut kemudian dihitung reliabilitasnya, dengan menggunakan koefisien alpha cronbach, koefisien reabilitasnya instrument yang dihasilkan apakah 
cukup atau tidak yang berarti instrument kualitas produk tersebut sudah dapat digunakan untuk pengambilan data penelitian.

$$
\boldsymbol{\alpha}=\frac{k}{k-1}\left(1-\frac{\sum S^{2} t}{S^{2} t}\right)
$$

Keterangan

a : Reabilitas Alpha Cronbach

$\mathrm{k} \quad$ : Jumlah butir instrument

$\sum S^{2} t$ : Jumlah varian butir

$S^{2} t \quad$ : Varian total

Varian butir ditentukan dengan rumus

$$
\sigma=\frac{\sum X^{2} \frac{\left(\sum X\right)^{2}}{n}}{n}
$$

Analisis dilakukan dari seluruh instrument. Kriteria pengujiannya adalah apabila nilai $\mathrm{r}_{\text {hitung }}>$ $\mathrm{r}_{\text {tabel }}$ maka intrumen dinyatakan reliabel dan sebaliknya apabila nilai $\mathrm{r}_{\text {hitung }}<\mathrm{r}_{\text {tabel }}$ maka instrument dinyatakan tidak reliabel.

\subsubsection{Variabel Pelayanan (Y)}

\subsubsection{Definisi Konseptual Variabel Keputusan Pembelian}

Keputusan pembelian adalah serangkaian proses atau tahapan yang dilalui konsumen untuk memilih dan benar-benar membeli satu yang paling disukai dibeberapa alternatif pilihan produk yang ada dengan indikator kebutuhan rasional, kebutuhan emosional, penguatan perhatian, keaktifan mencari informasi, harga produk, keramahan produk, pelayanan, yakin tepat untuk membeli, membeli pilihan utama.

\subsubsection{Definisi Operasional Variabel Keputusan Pembelian}

Keputusan pembelian diukur dengan menggunakan indikator (1) kebutuhan rasional, (2) keaktifan mencari informasi, (3) yakin tepat untuk membeli, dan (4) membeli pilihan utama.

\subsubsection{Kisi-Kisi Instrumen Keputusan Pembelian}

\begin{tabular}{|c|c|c|}
\hline Dimensi & Indikator & Butir Soal Angket \\
\hline $\begin{array}{l}\text { Kebutuhan } \\
\text { rasional }\end{array}$ & $\begin{array}{l}\text { Kebutuhan dan } \\
\text { keinginan akan } \\
\text { suatu produk. }\end{array}$ & 1,2 \\
\hline $\begin{array}{c}\text { Keaktifan } \\
\text { mencari } \\
\text { informasi }\end{array}$ & $\begin{array}{l}\text { mencari informasi } \\
\text { sebanyak-banyak } \\
\text { tentang produk } \\
\text { tangki air penguin } \\
\text { baik dr website } \\
\text { produk tersebut, } \\
\text { rekan, brosur, dll }\end{array}$ & 3 \\
\hline
\end{tabular}

Tabel 3. Kisi-Kisi Variabel Keputusan Pembelian 


\begin{tabular}{ccc}
\hline $\begin{array}{c}\text { Yakin dan } \\
\text { tepat } \\
\text { untuk }\end{array}$ & $\begin{array}{c}\text { Kemantapan akan } \\
\text { kualitas produk }\end{array}$ & 4,5 \\
membeli & & \\
\hline Membeli & Memutuskan & 6,7 \\
pilihan & produk yang & \\
utama & $\begin{array}{c}\text { dibeli, merupakan } \\
\text { yang terbaik. }\end{array}$ & \\
\hline
\end{tabular}

\subsubsection{Uji Coba Instrument Keputusan Pembelian}

Pengujian instrument kualitas produk untuk memilih untuk memilih butir-butir instrumen yang valid dan reliable.

\section{a. Pengujian Validitas}

Validitas yang diukur adalah validitas internal consistency dengan menggunakan rumus korelasi product moment. Antara skor butir soal dengan skor total.

$$
r b=\frac{n \sum X Y-\left(\sum X\right)\left(\sum Y\right)}{\sqrt{\left[n \sum X^{2}-\left(\sum X\right)^{2}\right]\left[n \sum Y^{2}-\left(\sum Y\right)^{2}\right]}}
$$

Keterangan

rb : Koefisien Korelasi Pearson Product Moment

$\mathrm{X} \quad$ : Skor item instrument yang akan digunakan

$\mathrm{Y} \quad$ : Skor semua item instrument dalam variabel tersebut

$\mathrm{n} \quad$ : Jumlah responden dalam uji coba instrument

Kriteria pengujian ditetapkan dengan cara membandingkan $r_{\text {hitung }}$ lebih besar dari $r_{\text {tabel }}$ maka butir instrument dikatakan valid, begitu sebaliknya $r_{\text {hitung }}$ lebih kecil atau sama dengan $r_{\text {tabel }}$ maka butir dinyatakan tidak valid (drop) sehingga tidak dapat digunakan untuk penelitian.

\section{b. Pengujian Reliabilitas}

Butir instrument yang telah dinyatakan valid tersebut kemudian dihitung reliabilitasnya, dengan menggunakan koefisien alpha cronbach, koefisien reabilitasnya instrument yang dihasilkan apakah cukup atau tidak yang berarti instrument kualitas produk tersebut sudah dapat digunakan untuk pengambilan data penelitian.

$$
\boldsymbol{\alpha}=\frac{k}{k-1}\left(1-\frac{\sum S^{2} t}{S^{2} t}\right)
$$

Keterangan

a : Reliabilitas Alpha Cronbach

$\mathrm{k} \quad$ : Jumlah butir instrumen

$\sum S^{2} t$ : Jumlah varian butir

$S^{2} t \quad$ : Varian total

Varian butir ditentukan dengan rumus 


$$
\sigma=\frac{\sum X^{2} \frac{\left(\sum X\right)^{2}}{n}}{n}
$$

Analisis dilakukan dari seluruh instrumen. Kriteria pengujiannya adalah apabila nilai $\mathrm{r}_{\text {hitung }}$ > $\mathrm{r}_{\text {tabel }}$ maka intrumen dinyatakan reliable dan sebaliknya apabila nilai $\mathrm{r}_{\text {hitung }}<\mathrm{r}_{\text {hitung }}$ maka instrumen dinyatakan tidak reliabel.

\subsubsection{Metode Pengumpulan Data, Populasi, dan Sampel Penelitian}

Sampel merupakan bagian atau sejumlah cuplikan tertentu yang dapat diambil dari suatu populasi dan diteliti secara rinci. Pengambilan sampel pada penelitian ini menggunakan teknik atau metode sample random sampling [10]. Sampel dipilih dari populasi secara acak, dimana setiap anggota populasi mempunyai hak yang sama untuk dijadikan sampel.

Dalam penelitian ini peneliti menggunakan penelitian asosiatif dan ekspalanasi, yaitu penelitian dengan penjelasan pengaruh, dan metode penelitian adalah analisis deskriptif, dimana data dikumpulkan, disusun, diinterpretasikan, dan dianalisis sehingga memberikan keterangan yang lengkap bagi masalah yang dihadapi. Data yang dikumpulkan meliputi identitas responden dan data mengenai tanggapan responden terhadap variabel-variabel yang mempengaruhi keputusan pembelian. Pengukuran variabel dilakukan dengan skala likert yang menggunakan metode scoring. Pada penelitian ini jumlah populasi tidak diketahui sehingga sampel yang diambil sebanyak 33 konsumen PT. Penguin Indonesia agar mewakilli populasi keseluruhan. Maka model penelitian ini digambarkan seperti dibawah ini:

Variabel $\mathrm{X}_{1}$ (Kualitas Produk)

(1) kinerja (performance)

(2) bagian-bagian tambahan dari produk (feature)

(3) kehandalan (reability)

(4) kesesuaian karakteristik operasi produkproduk dengan spesifikasi tertentu atau tidak ada cacat produk (conformance)

(5) ketahanan (durability)

(6) pelayanan (service ability)

(7) estetika (aesthetic)

(8) kesan kualitas (perceived quality)
(Kualitas Pelayanan)
(1) kecepatan
(2) ketepatan
(3) keramahan
(4) kenyamanan pelayanan

Variabel $\mathrm{X}_{2}$

Variabel Y

(Keputusan Pembelian)

(1) kebutuhan rasional

(2) keaktifan mencari informasi

(3) yakin tepat untuk membeli

(4) membeli pilihan utama

Gambar 2. Kerangka Pemikiran 


\section{HASIL DAN PEMBAHASAN}

\subsection{Karakteristik Penelitian}

\subsubsection{Jenis Kelamin}

Berdasarkan pengumpulan data responden terbanyak adalah Perempuan sebanyak 22 orang dengan presentase sebesar $67,67 \%$ dan laki-laki sebanyak 11 orang dengan presentase $33 \%$.

\subsubsection{Usia}

Berdasarkan pengumpulan data tingkat usia responden 19-30 sebanyak 15 orang dengan presentase sebesar $45,45 \%$. Tingkat usia $31-40$ sebanyak 10 orang dengan presentase $30,30 \%$ dan tingkat usia $>41$ sebanyak 8 orang dengan presentase $24,25 \%$.

\subsubsection{Pekerjaan}

Berdasarkan tabel diatas tingkat pekerjaan responden ibu rumah tangga sebanyak 16 orang dengan presentase sebesar $45,48 \%$. Pengusaha sebanyak 7 orang dengan presentase $21,21 \%$. Karyawan sebanyak 8 dengan presentase $24,24 \%$ dan pensiun sebanyak 2 orang dengan presentase $6,07 \%$.

\subsection{Uji Coba Instrument}

\section{a. Uji Validitas}

Uji vadilitas kepada 33 responden, analisis dilakukan terhadap semua butir instrument dari dua variabel independent yaitu kualitas produk $\left(\mathrm{X}_{1}\right)$, kualitas pelayanan $\left(\mathrm{X}_{2}\right)$ dan variabel dependent yaitu keputusan pembelian (Y). Dalam $r_{\text {tabel }}$ Pearson's Product Moment diketahui 0.3440 untuk n=33 dengan $\alpha=0,05$. Ketentuannya nilai $\mathrm{r}_{\text {hitung }}>\mathrm{r}_{\text {tabel, }}$ data dinyatakan valid, jika $\mathrm{r}_{\text {hitung }}<\mathrm{r}_{\text {tabel }}$ data dinyatakan tidak valid.

\section{b. Uji Reliabilitas}

Uji reliabilitas dilakukan kepada 33 responden dan perhitungannya menggunakan rumus alpha Cronbach's. Berikut hasil perhitungannya:

1. Kualitas Produk

Tabel 4. Case Processing Summary

\begin{tabular}{|rl|r|r|}
\hline & & \multicolumn{1}{|c|}{$\mathrm{N}$} & \multicolumn{1}{c|}{$\%$} \\
\hline \multirow{3}{*}{ Cases } & Valid $^{*}$ & 33 & 100.0 \\
& Excluded $^{\mathrm{a}}$ & 0 & .0 \\
& Total & 33 & 100.0 \\
\hline
\end{tabular}

Listwise deletion based on all variables in the procedure.

Tabel 5. Reliability Statistics

\begin{tabular}{|r|r|}
\hline $\begin{array}{c}\text { Cronbach's } \\
\text { Alpha }\end{array}$ & N of Items \\
\hline .927 & 15 \\
\hline
\end{tabular}


Berdasarkan output diatas nilai alpha 0.927 , nilai akan dibandingkan dengan nilai $r_{\text {tabel }}$, dengan jumlah $(n)=33$ maka didapat $r_{\text {tabel }}$ sebesar 0.3440. Nilai $r=0.927>0.3440$, maka item pada kualitas produk reliabel.

2. Kualitas Pelayanan

Tabel 6. Case Processing Summary

\begin{tabular}{|rl|r|r|}
\hline & & \multicolumn{1}{|c|}{$\mathrm{N}$} & \multicolumn{1}{c|}{$\%$} \\
\hline \multirow{3}{*}{ Cases } & Valid & 33 & 100.0 \\
& Excluded $^{\mathrm{a}}$ & 0 & .0 \\
& Total & 33 & 100.0 \\
\hline
\end{tabular}

Listwise deletion based on all variables in the procedure.

Tabel 7. Reliability Statistics

\begin{tabular}{|c|c|}
\hline $\begin{array}{c}\text { Cronbach's } \\
\text { Alpha }\end{array}$ & N of Items \\
\hline .895 & 10 \\
\hline
\end{tabular}

Berdasarkan output diatas nilai alpha 0.896 , nilai akan dibandingkan dengan nilai $r_{\text {tabel }}$, dengan jumlah $(n)=33$ maka didapat $r_{\text {tabel }}$ sebesar 0.3440. Nilai $r=0.895>0.3440$, maka item pada kualitas produk reliabel.

3. Keputusan Pembelian

Tabel 8. Case Processing Summary

\begin{tabular}{|rl|r|r|}
\hline & & \multicolumn{1}{|c|}{$\mathrm{N}$} & \multicolumn{1}{c|}{$\%$} \\
\hline \multirow{3}{*}{ Cases } & Valid $^{*}$ & 33 & 100.0 \\
& Excluded $^{\mathrm{a}}$ & 0 & .0 \\
& Total & 33 & 100.0 \\
\hline
\end{tabular}

Listwise deletion based on all variables in the procedure.

Tabel 9. Reliability Statistics

\begin{tabular}{|r|r|}
\hline $\begin{array}{c}\text { Cronbach's } \\
\text { Alpha }\end{array}$ & N of Items \\
\hline .867 & 7 \\
\hline
\end{tabular}

Berdasarkan output diatas nilai alpha 0.867 , nilai akan dibandingkan dengan nilai $r_{\text {tabel }}$, dengan jumlah $(n)=33$ maka didapat $r_{\text {tabel }}$ sebesar 0.3440. Nilai $r=0.8873>0.3440$, maka item pada kualitas produk reliabel.

\subsection{Uji Asumsi Klasik}

\subsubsection{Multikolinieritas}

Berdasarkan hasil besaran korelasi antar variabel independent tampak bahwa antara variabel angka rata-rata kualitas produk dan kualitas pelayanan memiliki korelasi -.34 (34\% = masih dibawah $90 \%$ ) maka dapat dikatakan tidak terjadi multikolieritas yang serius. 
Hasil Pengambilan keputusan dengan melihat VIF dan tolerance, dapat disimpulkan bahwa nilai tolerance $0.394>0.10$ dan nilai VIF $2.537<10$ maka tidak terdapat multikolineritas antar variabel independent.

\subsubsection{Autokorelasi}

Berdasarkan nilai diatas nilai DW $=1.838$ nilai DW akan dibandingkan dengan nilai tabel signifikasi 5\% dengan nilai $\mathrm{n}=33$ dan jumlah independent $\mathrm{K}=2$. Maka didapatkan nilai $\mathrm{dL}=1.3212$ dan nilai $\mathrm{dU}=1.577$. Nilai DW 1.870 lebih besar dari batas atas (dU) yaitu 1.577 dan kurang dari atau lebih kecil dari nilai (4-dU) 4-1.577 $=2.423$. Dengan demikian dapat disimpulkan niali DW terletak antara dU dan $(4-\mathrm{dU})=1.577<1.838<2.423$ maka hipotesis $\mathrm{H} 0$ diterima yang artinya tidak terdapat autokorelasi.

\subsubsection{Regresi Linier Berganda}

Berdasarkan output diatas terlihat bahwa nilai R (koefisien korelasi) sebesar 0.723 , yang berarti bahwa variabel dependent dan independent dapat dikatagorikan memiliki hubungan linier yang memiliki korelasi sangat kuat. Angka adjusted R square sebesar 0.522 atau sebesar $52 \%$ variabel independen yaitu kualitas produk dan kualitas pelayanan berpengaruh 52\% terhadap variabel dependen yaitu keputusan pembelian, sisa nya $48 \%$ dipengaruhi oleh hal lain diluar penelitian. Pengajuan hipotesis untuk Uji T \& Uji F sebagai berikut:

H0: Variabel independen (X) tidak berpengaruh secara signifikan terhadap variabel dependent. Ha: Variabel independen berpengaruh secara signifikan terhadap variabel dependent.

Pengujian terhadap kualitas produk diketahui nilai sig $0.000<0.05$ maka hipotesis H0 ditolak, artinya menerima hipotesis $\mathrm{Ha}$, yaitu secara parsial variabel kualitas produk $\left(\mathrm{X}_{1}\right)$ berpengaruh signifikan terhadap keputusan pembelian (Y). Pengujian terhadap kualitas pelayanan diketahui nilai diketahui nilai sig $0.362>0.05$ maka hipotesis H0 diterima, artinya secara parsial variabel kualitas produk $\left(\mathrm{X}_{2}\right)$ tidak berpengaruh signifikan terhadap keputusan pembelian $(\mathrm{Y})$.

Hasil pengujian F diketahui nilai sig uji F pada kualitas produk $0.000<0.05$ maka hipotesis $\mathrm{H} 0$ ditolak, artinya menerima hipotesis Ha, yaitu secara simultan (bersama-sama) variabel independen berpengaruh signifikasi terhadap variabel dependent yaitu keputusan pembelian. Dan hasil pengujian $\mathrm{T}$ Pengujian terhadap pengaruh kualitas pelayanan terhadap keputusan pembelian diketahui nilai sig. 0.362>0.05 maka hipotesis H0 diterima, artinya secara parsial variabel kualitas pelayanan tidak berpengaruh terhadap keputusan pembelian.

\subsubsection{Normalitas}




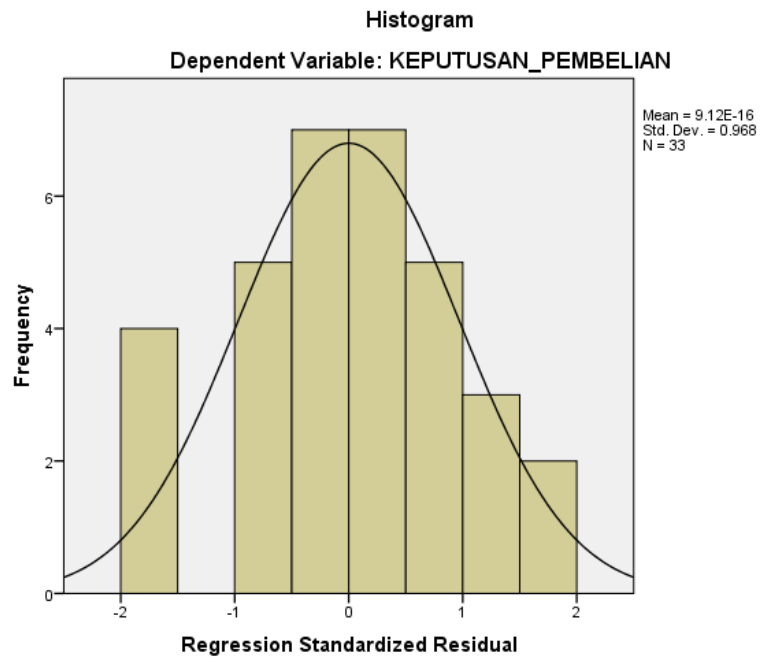

Gambar 4. Grafik Histogram

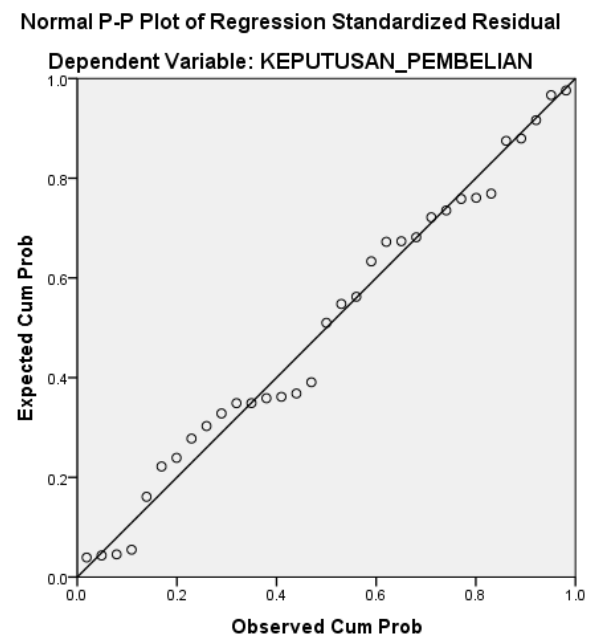

Gambar 5. Diagram Pilot

Berdasarkan tampilan ouput chart diatas grafik histogram dan grafik plot, dimana grafik histogram memberikan pola distribusi melenceng ke kanan yang artinya adalah data berdistribusi normal. Pada gambar P-Plot terlihat titik-titik mengikuti dan mendekati garis diagonal sehingga dapat disimpulkan bahwa model regresi memenuhi asumsi normalitas.

\section{KESIMPULAN}

Kesimpulan yang dapat diambil dalam penelitian ini adalah:

1. Secara Simultan (bersama-sama) variabel kualitas produk $\left(X_{1}\right)$ berpengaruh signifikan terhadap keputusan pembelian produk tangki pada PT Penguin Indonesia di Jakarta. Hal tersebut menunjukkan bahwa hipotesis pertama tentang dugaan adanya pengaruh bersama dari variabel-variabel bebas $(\mathrm{X})$ terhadap variabel terikat $(\mathrm{Y})$ dapat diterima.

2. Secara parsial variabel kualitas pelayanan $\left(\mathrm{X}_{2}\right)$ tidak berpengaruh signifikan terhadap keputusan pembelian produk tangki pada PT Penguin di Jakarta. 
3. Dari kedua variabel independent yang diteliti kualitas produk $\left(\mathrm{X}_{1}\right)$ dan kualitas pelayanan (X2), dapat terlihat bahwa variabel kualitas produk merupakan variabel yang memiliki pengaruh dominan.

\section{UCAPAN TERIMA KASIH}

Terima kasih kepada semua pihak yang telah membantu penelitian ini, terutama Mariyani.

\section{DAFTAR PUSTAKA}

[1] Gujarati, D N. 2012. Dasar-dasar Ekonometrika Edisi 5. Jakarta: Salemba Empat.

[2] Kodu, S. 2013. Harga, Kualitas Produk, dan Kualitas Pelayanan Pengaruhnya terhadap Keputusan Pembelian Mobil Toyota Avanza. ISSN: 2303-1174. Manado: Jurnal EMBA. Vol. 1, No. 3 September 2013: 1251-1259.

[3] Kotler, Philip. dan Keller, Kevin Lane. 2009. Manajemen Pemasaran Edisi 13. Jakarta: Erlangga.

[4] Sangadji, Etta Mamang dan Sopiah. 2015. Prilaku Konsumen. Yogyakarta: Andi.

[5] Sarwono, J. 2011. Buku Pintar IBM SPSS Statistic 19. Jakarta: PT. Elex Media Komputindo.

[6] Soewito, Yudhi. 2013. Kualitas Produk, Merek, dan Desain Pengaruhnya Terhadap Keputusan Pembelian Sepeda Motor Yamaha Mio. ISSN: 2303-1174. Manado: Jurnal EMBA. Vol. 1, No. 3 Juni 2013: 218-229.

[7] Sugiyono. 2012. Metode Penelitian Kuantitatif Kualitatif dan R\&D. Bandung: Alfabeta.

[8] Supranto, dan Nandan Limakrisna. 2012. Petunjuk Praktis Penelitian Ilmiah untuk Menyusun Skripsi, Tesis, dan Disertasi Edisi 3. Jakarta: Mitra Wacana Media.

[9] Sunyoto, Danang. 2015. Teori, Kuesioner \& Analisis Data untuk Pemasaran dan Prilaku Konsumen. Yogyakarta: Graha Ilmu.

[10] Surjaweni, V Wiratna. 2015. SPSS untuk Penelitian. Yogyakarta: Pustaka Baru.

[11] Weenas, Jackson R.S. 2013. Kualitas Produk, Harga, Promosi, dan Kualitas Pelayanan Pengaruhnya terhadap Keputusan Pembelian Spring Bed Comforta. ISSN: 2303-1174. Manado: Jurnal EMBA. Vol.1, No. 4 Desember 2013: 607-618 